\title{
The healthy management: the moderator role of transformational leadership on health workers
}

\author{
Ester Grau-Alberola ${ }^{1 *}$, Hugo Figueiredo-Ferraz², Jorge J. López-Vílchez ${ }^{3}$, and Pedro R. Gil-Monte ${ }^{3}$ \\ 1 Universidad Internacional de La Rioja (UNIR) (Spain), Unidad de Investigación Psicosocial de la Conducta Organizacional (UNIPSICO) \\ 2 Universidad Internacional de Valencia (VIU) (Spain), Unidad de Investigación Psicosocial de la Conducta Organizacional (UNIPSICO) \\ 3 Unidad de Investigación Psicosocial de la Conducta Organizacional (UNIPSICO). Universitat de València (Spain)
}

\begin{abstract}
Título: La gestión saludable: el rol moderador del liderazgo transformacional sobre la salud de los trabajadores.

Resumen: Los riesgos psicosociales derivados del trabajo, como la sobrecarga laboral, tienen un impacto negativo en la calidad de vida laboral, especialmente en el deterioro de las condiciones laborales y en la salud de los empleados. El estilo de liderazgo ejercido es clave en el afrontamiento de los riesgos psicosociales percibidos. El propósito de este estudio fue analizar la influencia del liderazgo transformacional y la sobrecarga laboral sobre los problemas psicosomáticos, y el papel moderador del liderazgo transformacional en la relación entre sobrecarga laboral y problemas psicosomáticos. La muestra consistió en 408 empleados españoles que trabajan con personas con discapacidad intelectual. Sobrecarga laboral y Problemas psicosomáticos se midieron con las subescalas UNIPSICO y Liderazgo transformacional se midió con una subescala adaptada del Cuestionario Multifactorial de Liderazgo (Bass \& Avolio, 1989). El análisis de moderación mediante PROCESS 3.4 mostró que tanto Sobrecarga laboral como Liderazgo transformacional tuvieron una influencia significativa sobre Problemas psicosomáticos. Además, Liderazgo transformacional moderó la relación entre Sobrecarga laboral y Problemas psicosomáticos. El liderazgo transformacional amortigua el impacto de la sobrecarga laboral en la salud de los empleados y, por lo tanto, se destaca la necesidad de implementar programas de capacitación para directivos en las organizaciones con el fin de ejercer una gestión saludable.

Palabras clave: Sobrecarga laboral. Liderazgo transformacional. Proble-
\end{abstract} mas psicosomáticos. Riesgo psicosocial. Estrés laboral.

\section{Introduction}

The emotional well-being of workers is related to an improvement in the state of health and the quality of interpersonal relationships, as well as the achievement of results at the organizational level (increased productivity and involvement in daily tasks, greater customer satisfaction and reduction of occupational diseases as well as rates of absenteeism and workplace presenteeism) (Johnson et al., 2018). Recent studies have highlighted the positive effects derived from the quality of working life, including promoting employee commitment and identification with the organization, as well as increasing job satisfaction (Akar, 2018; Bailey et al., 2020). Psychosocial risks can originate from working conditions that are related to direction, with the design and with the organization of the work, and with its organizational as well as the socialization processes or the style of leadership exercised (work overload, interpersonal conflicts, high levels of time pressure, low levels of participation in organization decisions, role ambiguity and job insecurity). In this case, the way in which workers face job demands will be decisive in

* Correspondence address [Dirección para correspondencia]: Ester Grau-Alberola. Universidad Internacional de La Rioja (UNIR). Av. de la Paz, 137, 26006, Logroño, La Rioja (Spain). E-mail: ester.grau@unir.net (Article received: 1-3-2021, revised: 23-6-2021, accepted: 29-6-2021)
Abstract: Psychosocial risks arising from work, like workload, have a negative impact on the quality of work life, especially in terms of the deterioration in working conditions and negative consequences for employees' health. The style of leadership exercised is key in coping with perceived psychosocial risks. The purpose of this study was to analyse the influence of transformational leadership and workload on psychosomatic disorders, and the moderating role of transformational leadership in the relationship between workload and psychosomatic disorders. The sample consisted of 408 Spanish employees working with people with intellectual disabilities. Workload and Psychosomatic disorders were measured by the UNIPSICO subscales, Transformational leadership was measured by a subscale adapted from the Multifactor Leadership Questionnaire (Bass \& Avolio, 1989). Carrying out moderation analysis in PROCESS 3.4 results showed that both Workload and Transformational leadership had a significant influence on Psychosomatic disorders. In addition, Transformational leadership moderated the relationship between Workload and Psychosomatic disorders. Transformational leadership buffers the impact of workload on employees' health and therefore in the need to carry out training programs for managers in organizations in order to exercise a healthy management. Keywords: Workload. Transformational leadership. Psychosomatic disorders. Psychosocial risk. Work stress. the consequences on their health. These working conditions are deteriorated, and have the potential to cause physical, mental and social harm to workers (Gil-Monte, 2016). In this sense, psychosocial hazards are defined as 'those aspects of work design and the organization and management of work, and their social and environmental contexts, which have the potential to cause psychosocial or physical harm' (Cox \& Griffiths, 1995). These psychosocial hazards relate to both the content (job content, workload and work pace, work schedule, environment and equipment) and the context of work (control, organizational culture and function including poor leadership, interpersonal relationships at work, role in the organization, career development, home-work interface) (Van Stolk et al., 2012). Nevertheless, the effects that the presence of psychosocial job risks can have on health are becoming a concern for organizations from a human and economic point of view. The management and proper treatment of psychosocial risks in the workplace still represents a complex task for some companies. Specifically, 21\% of European organizations perceive that these types of risks are more difficult to face than others due to difficulties such as the lack of awareness among workers and managers and the lack of experience or support from specialists (EU-OSHA, 2019).

Two of the most important variables being investigated in relation to employee health are workload and type of lead- 
ership (Hentrich et al., 2017). Workload represents a psychosocial risk related to the content of work that can occur either quantitatively (number of tasks to be carried out in a given time) or qualitatively (referring to the volume of information that must be processed in that time or the degree of difficulty that each task has) (Gil-Monte, 2016) being able to exceed the demands of the worker's response capacity. In this line, Eurofound (2019) highlights that the increase in intensity at work is positively associated with exhaustion, which in turn increases levels of presenteeism and symptoms related to psychosomatic disorders, reducing self-perceived health levels, the quality of sleep and the well-being of employees. Therefore work intensity is likely to impact negatively on health and wellbeing but nevertheless a higher level of resources in the social and labour spheres allows to reinforce the levels of commitment of the workers with their company, improving the quality of sleep, the levels of selfperceived health and reducing the symptoms related to psychosomatic disorders.

Today, work intensification has a negative impact on the quality of work life, especially in terms of the deterioration in working conditions and negative consequences for employee's mental and physical health (Eurofound, 2017; Van Aerden et al., 2016). In fact, several studies have found a relationship between workload and psychosomatic disorders (Gu et al., 2019; Heidarimoghadam et al., 2019; Oros et al., 2020). In this sense, it is important to highlight that long working hours (one of the direct consequences of high workload) is the third most frequent risk for health reported by almost $60 \%$ of establishments belonging to member countries of the European Union, according to the ESENER-3 survey (EU-OSHA, 2019).

The leadership style used in organizations is another influential variable in the development of psychosomatic disorders, the perception of psychosocial risks and in the psychological health of employees (Gilbert et al., 2017).

Holistic management of human resources is not limited to the mere direction of a set of technical skills, but covers a broader field of action, also focusing on other types of characteristics related to the emotions and intrinsic cognitions of each worker: interests, needs, perceptions, concerns, attitudes, etc. (Mohanraj, 2017). Many theories and definitions of leadership can be found in the literature (Gardner et al., 2020; McCauley \& Palus, 2020) Leadership can be defined as "the process of influencing others to understand and agree about what needs to be done and how to do it, and the process of facilitating individual and collective efforts to accomplish shared objectives" (Yukl, 2013, p. 7). From the "Full Range Leadership Development Theory' developed by Bass \& Avolio (1995) it is understood that there would be a continuum between the different leadership styles. There are two higher levels of leadership styles: transactional and transformational leadership. Transactional leadership represents the traditional type of manager, who identifies objectives, controls and manages resources, information and data, and monitors performance. In contrast, the transformational leader has a vision of the future and pursues continuing change, develops the potential of every collaborator, and accepts challenges (Bass \& Avolio 1995, Morsiani et al., 2017). In this sense, leadership is not a single trait, cognition, affect, or behaviour of an individual, but a system comprised of leader, follower, and situational elements (Sosik \& Jung, 2018).

Therefore, the behaviour and management style exercised by supervisors towards their workers represent a key element of intervention on psychosocial risks present in the workplace, as has been shown by the European reference institutions (Eurofound \& EU-OSHA, 2014). In the organizational context, the leader's behaviour influences his employees both positively and negatively, being able to develop dysfunctional leadership under certain circumstances (Shukla \& Shukla, 2020) or implementing competent and healthy leadership focused on organizational and individual development. In addition, the processes through which the leader's behaviour can influence the health of employees could be as Nyberg (2009) hypothesized by three ways: (a) directly influencing the stress reactions of employees; or (b) influencing the working conditions, which increase or decrease stress; or (c) buffering the potential effects on the stressor-strain relationships.

As the organization leader, he or she is able to detect the situation of workload suffered by his employees throughout the practice or behaviour he or she develops within his/her group, helping them to manage them appropriately, applying the necessary changes to redistribute the tasks, and guiding them towards more appropriate levels (St-Hilaire et al., 2018). In this way, they constitute themselves as true agents of change capable of directly or indirectly influencing the attitudes and occupational health of their workers, providing them with the support they need: offering feedback, resolving situations of conflict or encouraging their participation within the company (Montano, 2016; Toderi et al., 2015).

Based on ideas originally proposed by Burns (1978), Bass $(1985,1997)$ defined transformational leadership as a leadership style characterized by four dimensions: Idealized Influence or Charisma (the degree to which the leaders display conviction; emphasize trust; take stands on difficult issues and emphasize the commitment, values and the ethical consequences of decisions), Inspirational Motivation (the degree to which the leaders articulate an appealing vision of the future, challenge followers with high standards, talk optimistically with enthusiasm, and provide encouragement), Intellectual Stimulation (the degree to which the leaders question traditions, and beliefs; stimulate in others new perspectives; and encourage the expression of ideas and reasons) and Individualized Consideration (the degree to which the leaders deal with others as individuals; consider their individual needs, abilities, and aspirations; listen attentively; further their development; advise; teach; and coach). The Multifactor Leadership Questionnaire (MLQ) (Bass \& Avolio, 1989) developed from the 'Full Range Leadership Development Theory' allows to identify the presence or absence of the transformational leadership 
dimensions. As Lievens et al. (1997) pointed out the four scales were highly intercorrelated and clustered into one single factor. Based on these results the MLQ would be able to measure a global transformational leadership dimension and would fail to discriminate among the four dimension of transformational leadership.

Previous studies focus on the characteristics of transformational leadership, which are associated with well-being (Arnold, 2017), health, productivity (Chebon et al., 2019; Erskine \& Georgiou, 2017; Skakon et al., 2010), quality of work life (Akar \& Ustuner, 2019), job satisfaction (Dumdum et al. 2013; Kedenburg, 2014; Morsiani et al., 2017; Specchia et al, 2021) and a reduction of levels of absenteeism, sick leaves and employee replacement rates (Erskine \& Georgiou, 2017).

Both workload and transformational leadership have been associated with psychosomatic disorders. Situations of excessive workload contribute to the deterioration of the individual's physical and psychological health (Gonzalez-Mulé \& Cockburn, 2020) and some studies have shown that transformational leadership positively predicts positive measures of well-being (Arnold, 2017). Moreover, recent studies have found a moderating role of transformational leadership in the relationship between some psychosocial risks and its consequences to workers (such as psychosomatic disorders and turnover intention among others) (Abbasi, 2018; Syrek et al., 2013). Definitely, transformational leaders may influence the way employees perceive their work characteristics, due to personal attention, individual consideration, intellectual stimulation, and coaching (Hentrich et al., 2017).

Specifically, working in intellectual disabilities (IDs) care sector can be stressful (Hatton et al., 1999; Kozak et al., 2013). Research findings within the field of ID indicate that there are various psychosocial stressors and resources at work which are related to burnout and personal distress. Hatton et al. (1999) identified some stressors related to distress (wishful thinking, work-home conflict, role ambiguity), job strain (wishful thinking, a lack of staff support, alienative commitment, role ambiguity, a low status job, working longer contracted hours) and work satisfaction (a low status job, support from supervisors, influence over work decisions, alienative commitment, support from colleagues and older staff age). The characteristics of the jobs indicate that there is usually low income, a lack of training, the perceived low status of workers and long contracted hours (Cathal et al., 2021). Care staff have also high-lighted problems relating to work-privacy conflict, emotional demands, role conflicts, job insecurity, feedback, higher rates of intention to leave the job and cognitive stress symptoms (Kozak et al., 2013).

In relation to the characteristics of the sample, although several studies have indicated significant differences based on sex and age, the results are not conclusive. The literature on male-female differences has produced inconsistent results regarding the strength and direction of the relationship with well-being and job satisfaction. Van der Meer (2018) found a weak negative correlation between female gender and well-being, women reported lower levels of wellbeing than did men. The findings pointed out in the study by Haile (2012) with a sample of 18.064 employees in 1506 workplaces in relation to gender suggest a link related to group size between female gender and job satisfaction. In the studies carried out in which the majority of the sample are women, a negative and significant association is found between workplace gender diversity and job satisfaction. Other studies have indicated that there is a clear difference between both sexes, presenting men higher levels of burnout and emotional exhaustion that women. In relation to age, it has been found that older employees in the ID care sector are more involved in their work and tend to better detect the needs of their clients and their own needs, thus increasing their job satisfaction (Van der Meer, 2018) but other studies pointed out that in this population employees with 50 years or older have very high levels of burnout (Llorent \& RuizCalzado, 2016).

In this context of care, social support is the resource that has been investigated most extensively in connection with burnout specially the support given by supervisors (Kozak et al., 2013). Perceived social support, adaptive coping strategies and higher self - efficacy in dealing with challenging behaviours are identified as compensatory factors to reduce the risk of developing burnout symptoms among staff supporting individuals with IDs (Klaver et al., 2021; Devereux et al., 2009). As Cox et al. (2021) pointed out up to 50\% of individuals with intellectual and developmental disabilities engage in problem behaviour including self-injury, aggression, disruption, property destruction, pica, stereotypy, elopement, and inappropriate sexualized behaviours. Other studies demonstrated that there is a relationship between challenging behaviour and burnout that is mediated by negative emotion as the fear of potential assault (Mills \& Rose, 2011). Coping with these situations requires material and human resources as specialized training and competent leadership. In fact, receiving little training and support has been identified as a source of stress on staff working with people with IDs (Klaver et al., 2021).

The aim of this study was to analyse the influence of transformational leadership and workload on psychosomatic disorders, and the moderating role of transformational leadership in the relationship between workload and psychosomatic disorders. Taking into consideration this objective, the hypotheses proposed are:

Hypothesis 1. A significant positive relationship is expected between Workload and Psychosomatic disorders.

Hypothesis 2. A significant negative relationship is expected between Transformational leadership and Psychosomatic disorders.

Hypothesis 3. Transformational leadership will moderate the positive relationship between Workload and Psychosomatic disorders.

H 3.1: In high workload situations, individuals who perceive higher levels of Transformational leadership 
will present significantly fewer Psychosomatic disorders.

H 3.2 : In high workload situations, individuals who perceive lower levels of Transformational leadership will present significantly more Psychosomatic disorders.

\section{Method}

\section{Participants}

The sample consisted in 639 Spanish employees working with people with intellectual disabilities at 61 companies in the Valencian Community (Spain). Finally, 408 employees participated and the response rate was $63.85 \%$. With regard to gender, $78(19.1 \%)$ participants were men, and 318 $(77.9 \%)$ were women. 12 participants $(3 \%)$ did not answer this question. Their mean age was 39.04 years $(S D=9.059$; range: $22-70) .318$ workers had permanent contracts $(77.9 \%)$ and 90 eventual contracts $(22.1 \%)$. They had a mean of 12.02 years of experience in the profession $(S D=7.82$; range: $0-43$ years). With regard to occupation, the highest percentage of participants worked as personal care assistants $(23.7 \%)$ and educators $(29.9 \%)$. The remaining participants worked as managers $(10.4 \%)$, health professionals $(9.0 \%)$, psychologists $(7.8 \%)$, occupational therapists $(4.3 \%)$, cleaners and maintenance technicians $(3.8 \%)$, administrative assistants $(2.8 \%)$, stimulation technicians $(2.6 \%)$, cooks $(2.1 \%)$, social workers $(1.2 \%)$, speech therapists $(1.2 \%)$ and other jobs $(1.2 \%)$. The job centres were selected in a random way taking into account the population of job centre that provide attention and care for people with ID (25 occupational centres, 18 residential centres, 7 stimulation centres, 7 day centres and 4 rehabilitation and social integration centres) in the Valencian Community (Spain).

\section{Instruments}

Workload was assessed by the UNIPSICO subscale (GilMonte, 2016) (6 items, $\alpha=.75$ ). Participants answered the items on a 5 -point scale ranging from "Never" (0) to "Very frequently" (4).

Transformational leadership was measured by a subscale adapted from the Multifactor Leadership Questionnaire (Bass \& Avolio, 1989) (12 items, $\alpha=.96)$. Participants indicated the frequency with which their superiors initiated the four main components that define transformational leadership: stimulation (3 items), inspiration ( 3 items), individualized consideration (3 items) and charisma (3 items), using a 5 -point scale from 0 "Never" to 4 "Very frequently: every day".

However, based on previous research (Hentrich et al., 2017; Holstad et al., 2014; Lievens et al., 1997) these subdimensions occur to be highly interrelated, so the total score for the construct was used.

Psychosomatic disorders were also measured by the UNIPSICO scale (Figueiredo-Ferraz et al., 2013) (9 items; $\alpha=.87$ ). Items included different work-related psychosomatic disor- ders (e.g.: headaches, musculoskeletal pain, sleep quality, anxiety, and sickness) (e.g.: Have you had contractures or muscle aches?). Participants answered the items on a 5 -point frequency scale ranging from "Never" (0) to "Very frequently: Every day" (4).

\section{Procedure}

The job centres were selected in a random way, taking into account the population of job centres that provide attention and care for people with intellectual disabilities (stimulation centres, occupational centres, day centres and residential centres) in the Valencian Community (Spain). The researchers contacted the managers of all the selected centres to ask for permission to use a questionnaire. Then, all of the workers at the selected centres were asked to fill out the inventory. This study respected the fundamental principles of the Declaration of Helsinki (World Medical Association, 2013), with particular emphasis on the anonymization of the data collected, confidentiality, and non-discrimination of participants. Participation was voluntary and anonymous. Completed surveys were put each into an envelope by the participant, guaranteeing confidentiality, and send back to the researchers. The participants were informed that by filling in the questionnaires they agreed to participate in the study. The study was approved by the Investigation Committee of the Faculty of Psychology, University of Valencia.

\section{Statistical analysis}

First, descriptive statistics and correlations between the variables under study were calculated. Next, multiple regression analyses were performed using the PROCESS 3.4 macro for SPSS (Hayes, 2018) to study the moderating role of the Transformational leadership variable within the relationship established between Workload and Psychosomatic disorders. For this, model 1 (simple moderation model) with a $95 \%$ confidence interval and a number of bootstrapping samples of 10000 was selected. To avoid possible multicollinearity problems, the mean centering technique was applied to the predictor variables Workload and Transformational leadership. This technique consists of subtracting the value of the predictor mean from each of its scores, so that the value of the new centered predictor mean is zero. The application of mean centering allows to reduce the statistical problems associated with the high correlation between the predictor variables (of .90 or greater) and facilitates the subsequent interpretation of the coefficients associated with the terms that are part of the interaction (Aguinis et al., 2017). Finally, the Johnson-Neyman technique was used to delimit the regions of statistical significance, allowing to observe specifically the effect of the independent variable (Workload) on the dependent variable (Psychosomatic disorders) for different values of the moderating variable (Transformational leadership). 


\section{Results}

The reliability of the scales, using Cronbach's alpha, were adequate, with results above .70 (Nunnally, 1978). The analyses carried out indicate that there were no collinearity problems.

Table 1 shows the means, standard deviations, range, correlations, and internal consistencies of all the scales in- cluded in this study. The analyses indicated statistically significant associations between the variables under study: (1) Workload was negatively related to Transformational leadership $(r=-.17, p<.001)$ and positively with Psychosomatic disorders $(r=.42, p<.001)$; (2) Transformational leadership was negatively related to Psychosomatic disorders $(r=-.36, p$ $<.001)$.

Table 1

Means, Standard Deviations, Range, Correlations and Internal Consistencies (Cronbach's alphas on the diagonal)

\begin{tabular}{|c|c|c|c|c|c|c|}
\hline & $M$ & $S D$ & Range & 1 & 2 & 3 \\
\hline 1. Workload & 1.77 & .69 & $0-4$ & .75 & & \\
\hline 2. Transformational leadership & 1.70 & .96 & $0-4$ & -.17 & .96 & \\
\hline 3. Psychosomatic disorders & 1.11 & .73 & $0-4$ & .42 & -.36 & .87 \\
\hline
\end{tabular}

Note. All values were significant at $p<.001$

To test the hypotheses, hierarchical moderated multiple regression analyses were performed. To control the association of Psychosomatic disorders with individual measures, regression models were designed to include a first step that contained two control variables: sex and age. Next, the main effects associated with Workload were included in the second step, followed by the effects of Transformational leadership and finally in the fourth step the interaction among Workload $(X)$ and Transformational leadership $(W)$.

Table 2 shows the results of the non-standardized regression coefficients calculated using the PROCESS macro, along with the corresponding confidence intervals. To carry out these analyses, the mean-centering technique was previously applied to the predictor variables: Workload $(X)$ and Transformational leadership $(W)$.

Firstly, the $R^{2}$ coefficient allows us to indicate the quality of the regression model proposed, being the model tested significant, allowing to explain $28 \%$ of the total variance of the criterion variable (Psychosomatic disorders) $\left(R^{2}=.28, F\right.$ $=30.77, p<.001$ ).

The following linear regression analyses were performed: (1) of the control variables: sex and age, (2) of the independent variable $(X)$ on the dependent variable $(Y)$; (3) from the moderating variable $(W)$ over the dependent variable $(Y)$; and (4) of the interaction between the independent variable and the moderating variable $(X W)$ on the dependent variable $(Y)$. The estimates of each regression analysis were made using the values of the coefficients obtained (not standardised) together with those corresponding to the level of significance, defined by the value of $p$ and by the lower and upper limits (LLCI, ULCI) of the confidence interval (CI). If the value 0 is within this range, the regression analysis will be insignificant. The results obtained confirm the hypotheses raised. Significant values were obtained for both the independent variable (Hypothesis 1): significant and positive effect of Workload on Psychosomatic disorders $(b=.38, p<$ $.001,95 \%$ CI $[.28, .47])$; as for the moderating variable (Hypothesis 2): significant and negative effect of Transformational Leadership on Psychosomatic disorders $(b=-.23, p$ $<.001,95 \%$ CI $[-.30,-.17])$. Taking into account the variable
Sex, significant differences were found $(b=.16, p<.05,95 \%$ $C I[.00, .31])$ but not with the variable Age $(b=.00, p>.05$, $95 \%$ CI $[-.00, .01])$. Finally, for interaction between the independent and moderating variable, (Hypothesis 3.1 and $\mathrm{Hy}-$ pothesis 3.2), significant and negative moderating effect of Transformational Leadership in the relationship between Workload and Psychosomatic disorders $(\theta X \rightarrow Y \mid W=$ $.11, p<.05,95 \%$ CI [-. 20,-.02]) was found. The results show that both variables (Workload and Transformational Leadership) have a significant influence on Psychosomatic disorders. In addition, transformational leadership acts as a moderating variable in the relationship between both variables, allowing to mitigate the detrimental effects on the health of workers exposed to excessive levels of workload.

Table 2

Unstandardized OLS Regression Coefficients with Confidence Intervals. Estimating Psychosomatic disorders. Workload and Transformational leadership are Mean Centered.

\begin{tabular}{lllll}
\hline & \multicolumn{4}{c}{ Psychosomatic disorders $(Y)$} \\
\cline { 2 - 5 } Step and Predictors & Coeff. & SE & LL & UL \\
\hline Constant & $.64^{* *}$ & .20 & .24 & 1.04 \\
Control Variables & & & & \\
$\quad$ Sex & $.16^{*}$ & .08 & .00 & .31 \\
$\quad .00$ & .00 & -.00 & .01 \\
$\quad$ Age & $.38^{* * *}$ & .04 & .28 & .47 \\
Workload $(X)$ & $-.23^{* * *}$ & .03 & -.30 & -.17 \\
Transformational lead- & & & & \\
ership $(W)$ & $-.11^{*}$ & .04 & -.20 & -.02 \\
$X \mathrm{x} W$ & & & &
\end{tabular}

$$
\begin{aligned}
& \mathrm{R}^{2}=.28 \\
& \mathrm{~F}=30.77, p<.001
\end{aligned}
$$

Note. $S E=$ Standard error; $L L=$ Lower limit; $U L=$ Upper limit; $R^{2}=$ Multiple correlation squared; $F=$ Fisher's $F$ ratio. Confidence intervals $(C I)$ with no zero in the range are significant. Bootstrap CI based on 10000 bootstrap samples.

${ }^{*} p<.05,{ }^{* *} p<.01,{ }^{* * *} p<.001$

Figures 1 and 2 graphically represent the model proposed from a conceptual and statistical point of view. Specifically, Figure 2 includes the value of the regression coefficients calculated for each of the variables studied. 
Figure 1

Graphic representation of the study model: conceptual and statistical diagram.

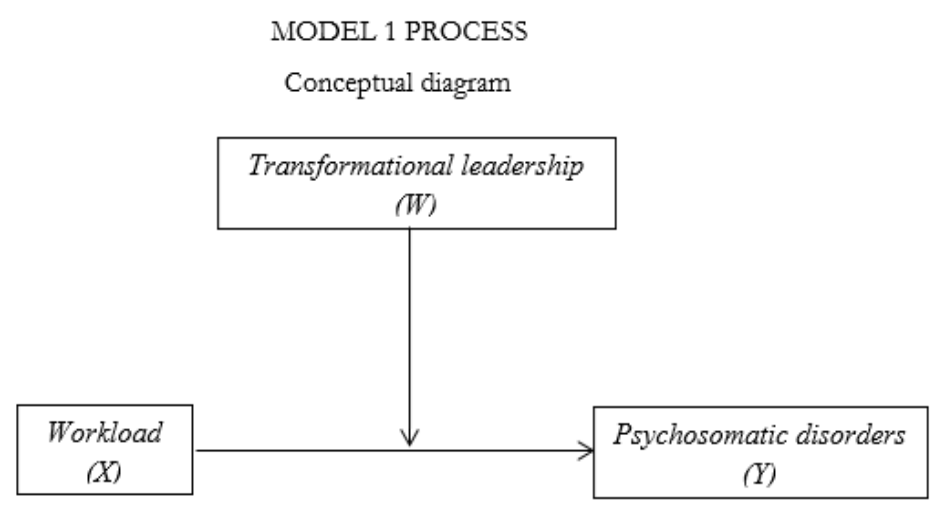

Statistical diagram

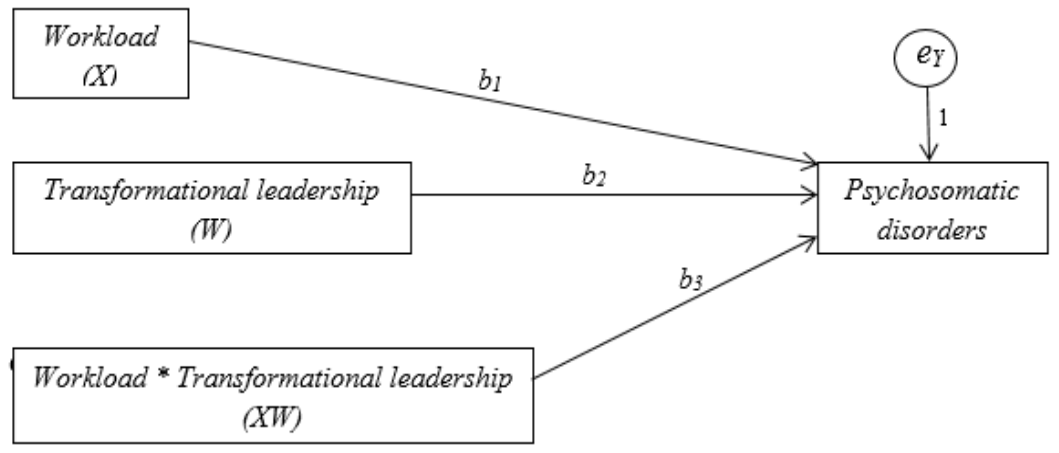

Figure 2

Results of the regression analysis with the PROCESS macro (statistical diagram).

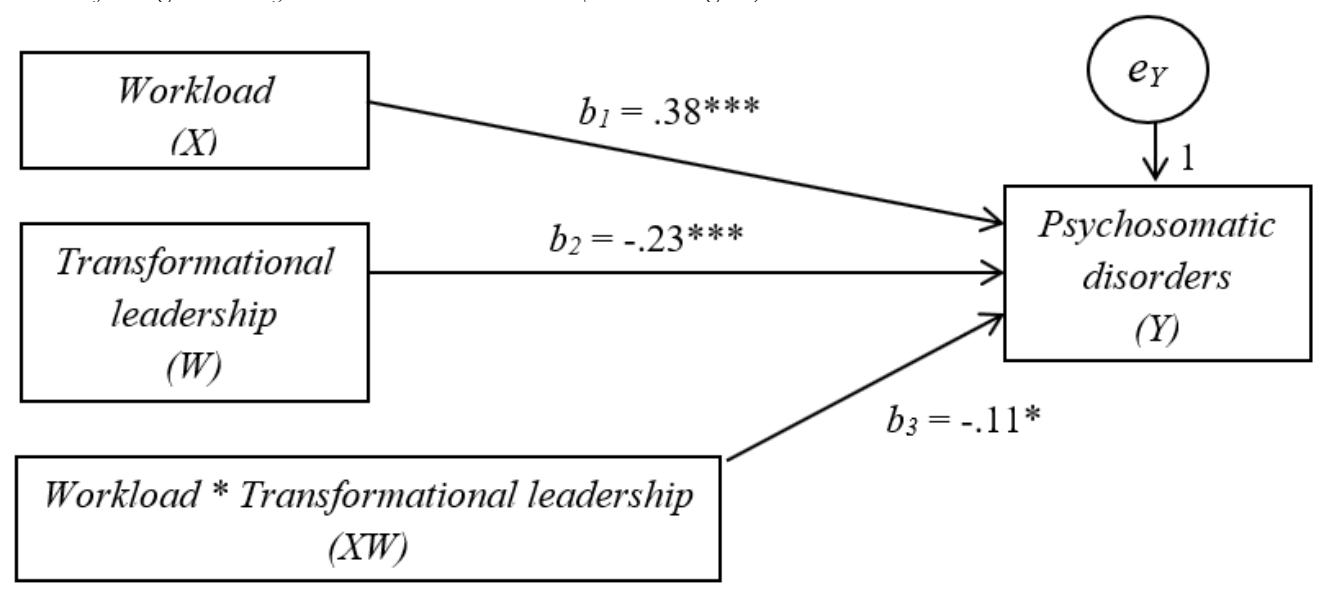

Figure 3 graphically represents the interaction effect (moderation) of the variable Transformational leadership in the relationship established between Workload and Psychosomatic disorders. Using the pick-a-point technique, PROCESS provides three different values for the moderating var- iable, calculated from the mean score +/- 1 times its standard deviation. These values were labelled as (1) low perception (value of -.96); (2) medium perception (value of .00) and (3) high perception (value of .96). 
The graph shows that the effect of Workload on Psychosomatic disorders was statistically significant in low perception conditions $(\theta X \rightarrow Y \mid W=$ low $=.49, p<.001,95 \% C I$ $[.36, .61])$, medium perception $(\theta \mathrm{X} \rightarrow \mathrm{Y} \mid \mathrm{W}=$ medium $=$ $.38, p<.001,95 \%$ CI $[.29, .47])$ and high perception $(\theta X \rightarrow$ $Y \mid W=$ high $=.27, p<.001,95 \%$ CI $[.15, .40])$. Therefore, in situations of Workload, the medium or high perception of Transformational leadership significantly reduces the levels of Psychosomatic disorders. On the other hand, in situations of high Workload, the low perception of Transformational leadership significantly increases the levels of Psychosomatic disorders.

\section{Figure 3}

Graphical representation of the moderating effect of the Transformational leadership variable (low, medium and high perception) on the relationship between Workload and Psychosomatic disorders.

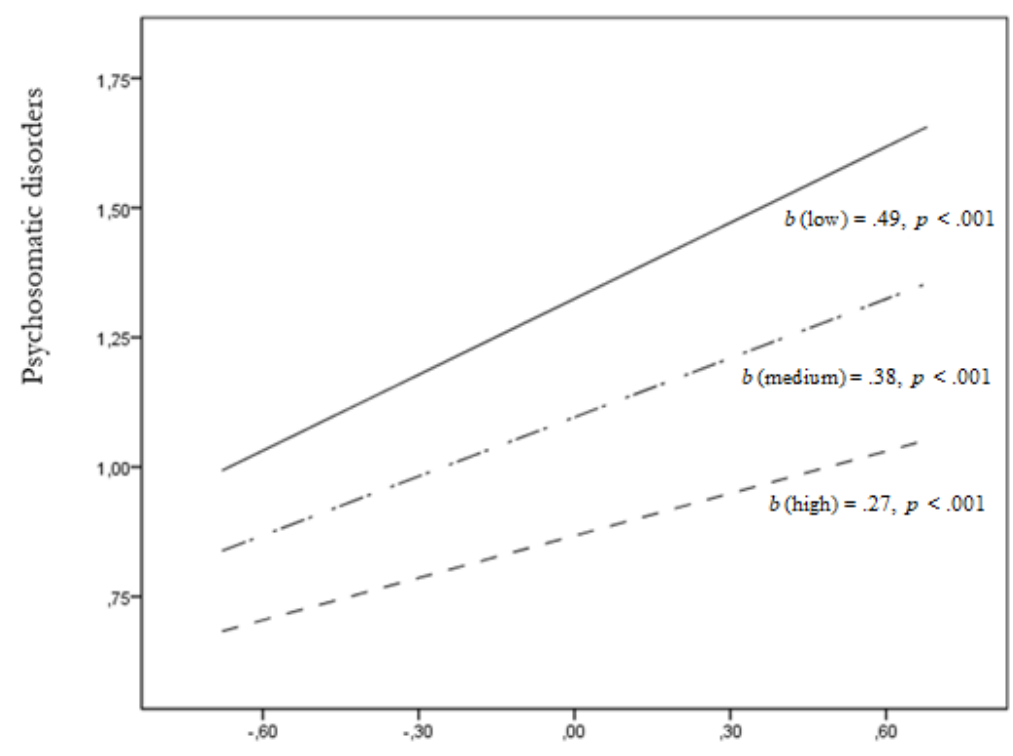

Workload

Finally, Figure 4 represents the conditional effect of Workload on Psychosomatic disorders for the different values adopted by the moderating variable (Transformational Leadership), using the Johnson-Neyman technique. This graph defines the region of statistical significance, the one in which the conditional effect studied between variables $X$ and $Y$ is statistically significant for the different values of Transformational leadership $(W)$. This region is represented in the first quadrant of the graph (upper left quadrant). It is observed that the effect of Workload on Psychosomatic disorders (represented in the line titled as Point Estimate) is statis- tically significant when $\mathrm{W}$ has a score less than 1.75 , while it ceases to be so from scores equal or higher than this value (quadrant upper right), leaving $96.21 \%$ of the sample below this value and $3.79 \%$ above.

Therefore, the effect of Workload on Psychosomatic disorders $(\theta X \rightarrow Y)$ is conditioned by the variable Transformational leadership $(\theta X \rightarrow Y \mid W)$, which significantly moderates the causal relationship studied, in such a way that its intensity is gradually reduced as the perception of Transformational leadership increases. 
Figure 4

Graphic representation of the conditional effect of Workload on Psychosomatic disorders as a function of the different values of the moderating variable (Transformational Leadership).

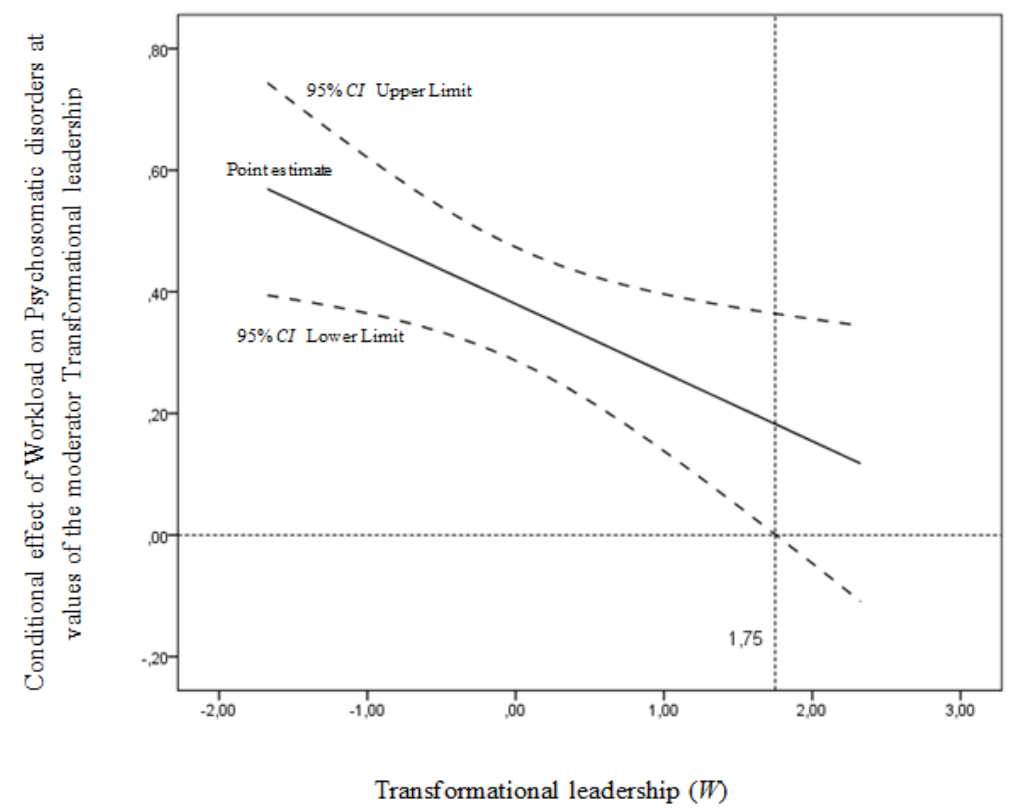

\section{Discussion}

This study contributes to the research on psychosocial risks at work by offering support for the assumption that transformational leadership buffers the impact of workload on employees' health (Green et al., 2013). We propose that employees who feel low or medium workload pressure have fewer psychosomatic disorders, even in the absence of transformational leadership. By contrast, when workload produces high levels of strain on workers' health, the presence of transformational leadership reduces workload's impact on their health. Thus, in environments characterized by high levels of workload, employees who perceive that their managers are using a transformational leadership style will have lower levels of psychosomatic disorders than employees who do not perceive this style. Day et al. (2004) suggested that the overall leadership capacity of an organizational entity is a form of social capital that involves sharedness and distributed influence. In this regard, the concept of shared leadership arises as an emergent team property of mutual influence and shared responsibility among team members (Wang et al., 2014). Therefore, in terms of our results, transformational leadership is understood as a formed of shared leadership, characterized by distributing the influence and responsibility among team members who have the same objective in the organization. Recent approaches view effective leadership less as a process focused exclusively on the leader's decisions and more as a decision-making process emerging from lower levels (Wang et al., 2014). So different styles of leadership contribute to different aspects of team effectiveness, in fact, transformational leadership contributed to team output effectiveness (Choi et al., 2017). Thus the leadership style may be moderating the relationship between psychological risks on the employees' health.

Therefore, transformational leadership is effective insofar as it influences the characteristics of work and satisfies the needs of workers (Breevaart et al., 2014).

Taking into account its main components, transformational leadership generates a process of influence at the cognitive and emotional level. The leader represents and defends the beliefs and values of the organization but has an emotional aspect that involves the adherence of workers to the well-being of the group (Ribeiro et al., 2018) The way in which each of the components influences the interaction between the worker and the organization itself is decisive to understand that the leader's function surpasses the purely circumscribed aspects of the task, thus relating to the affective organizational commitment and followers' effectiveness (Pierro et al., 2013, Noreen et al., 2021) and in this sense, organizations can exercise and improve healthy leadership. This involves both behavioural, cognitive and emotional aspects, taking into account the link between workers and manager. So, healthy management is a way to understanding organizations as two-way links.

Leadership as socio-emotional support moderates the relationship between perceived stressors and their consequences, as demonstrated in this study in high-stress situations. This buffering function has been related to the wellbeing of workers (Arnold, 2017), greater job satisfaction 
(Syrek \& Antoni, 2017) as well as being decisive in their performance and motivation (Chua \& Ayoko, 2019).

Recent studies suggest that the relation between transformational leadership and workers health may better be explained due to the reduction of job demands and an enhancement of personal resources (Hentrich et al., 2017). In addition, leadership style plays a key role in the construction of working relations. The general well-being and productivity of employees is related to healthy work environments that take care of their workers. A staff-oriented leadership facilitates health and personal development (Kozak et al., 2013). Particularly in working with people with intellectual disabilities, it is important to invest in potential resources and coping mechanisms. In fact, it has been shown that supervisor support by providing adequate feedback on work as well as recognition of personal achievement can mitigate risks.

A significant fluctuation in the leader's behaviour has been found so that under certain circumstances of high perception of psychosocial risks and depending on the type of demand, transformational leadership can help increase workers engagement. Employees need to perceive and feel confident in the leader in situations that can be highly stressful. The external circumstances of the task and the organization may be more difficult to change but investing in the training of managers and in healthy strategies for the worker reduces the consequences on physical and psychological health that may arise. This fact is particularly interesting when proposing interventions aimed at training leaders (Breevaart \& Bakker, 2018).

Thus, the individual perception that the worker has determines the engagement with the values of the company, resulting in greater individual and collective satisfaction. In fact recent studies show the importance of the individual perception of workers and the expectations regarding what a leader should provide them (need for leadership) in the effectiveness of transformational leadership in terms of needs met. Therefore, a dependency relationship would be established with the leader's behaviour in those workers who have a high need for leadership, trusting him/her more than the workers

\section{References}

Abbasi, S. G. (2018). Leadership styles: Moderating impact on job stress and health. Journal of Human Resources Management Research, 1-11. Article ID 322892 http://dx.doi.org/10.5171/2018.322892

Aguinis, H., Edwards, J. R., \& Bradley, K. J. (2017). Improving our understanding of moderation and mediation in strategic management research. Organizational Research Methods, 20(4), 665685.https://doi.org/10.1177/1094428115627498

Akar, H. (2018). A meta-analytic study concerning the effect of educational stakeholders' perceptions of quality of work life on their job satisfaction and organizational commitment. International Online Journal of Educational Sciences, 10(3), 99-112. http://dx.doi.org/10.15345/iojes.2018.03.007

Akar, H., \& Ustuner, M. (2019). The relationships between perceptions of teachers' transformational leadership, organizational justice, organizational support and quality of work life. International Journal of Research in Education and Science (IJRES), 5(1), 309-322.

Arnold, K. A. (2017). Transformational leadership and employee psychological well-being: a review and directions for future research. Journal of $\mathrm{Oc}$ - with less need for leadership and would act more independently (Breevaart, et al. 2014). Some studies point out that relational identification plays a crucial role in subsequently shaping collective identifications, in this sense transformational leadership is more strongly associated with leader identification than with organizational identification or team identification (Horstmeier et al., 2017).

\section{Conclusions}

This paper addresses an interesting and important issue in relation to health prevention and improvement in the workplace. Our study provides support for introducing a way to prevent the psychosomatic disorders caused by workload in teams. Studies confirm the importance of leadership functions oriented toward change in teams (Wang et al., 2014), and they recommend training in transformational leadership in services for people with intellectual disabilities (BeadleBrown et al., 2015). Leaders need to be competent and trained in the process of transforming organizations trying to reduce the hierarchical space between them and their followers though new approaches of supervision that can improve employee's performance, well-being and growth (Peláez et al., 2021). In this line, recent studies highlight the importance of an integrative approach to leadership where followers need to be considered as active elements and the leader has the characteristics of authentic leadership (self-awareness, relational transparency, balanced processing, and internalized moral perspective) within a process of mutual influence in which group cohesion and organizational commitment could be developed (Fladerer \& Braun, 2020, García-Guiu et al., 2015; Edú et al., 2012; Moriano et al., 2011).

The main limitations of the current study are its crosssectional nature. There is a need to carry out longitudinal studies and consider a more balanced sample with regard to the sex variable. Futhermore, new organizational strategies based on the emotional aspect are required in order to improve leadership and its relationship with workers health. $\begin{array}{lll}\text { cupational Health Psychology, 22(3), 381-393. } & \text {. }\end{array}$ https://doi.org/10.1037/ocp0000062

Bailey, T. S., Owen, M. S., \& Dollard, M. F. (2020). Psychosocial factors and worker health: comparisons between private and public sectors in Australia. In Handbook of Research on Stress and Well-Being in the Public Sector. Cheltenham, UK: Edward Elgar Publishing. https://doi.org/10.4337/9781788970358.00011

Bass, B. M. (1985). Leadership and performance beyond expectations. Free Press.

Bass, B. M. (1997). Does the transactional-transformational leadership paradigm transcend organizational and national boundaries? American Psychologist, 52(2), 130-139. http://dx.doi.org/10.1037/0003-066X.52.2.130

Bass, B. M., \& Avolio, B. J. (1989). Manual for the Multifactor Leadership Questionnaire. Consulting Psychologists Press.

Bass, B. M., \& Avolio, B. J. (1995). Manual for the multifactor leadership questionnaire: Raterform ( $5 X$ short). Palo Alto, CA: Mind Garden.

Beadle-Brown, J., Bigby, C., \& Bould, E. (2015). Observing practice leadership in intellectual and developmental disability services. Journal of Intel- 
lectual Disability Research, 59(12), 1081-1093. https://doi.org/10.1111/jir.12208

Breevaart, K., \& Bakker, A. B. (2018). Daily job demands and employee work engagement: The role of daily transformational leadership behaviour. Journal of Occupational Health Psychology, 23(3), 338-349. https://doi.org/10.1037/ocp0000082

Breevaart, K., Bakker, A. B., Demerouti, E., Sleebos, D. M., \& Maduro, V. (2014). Uncovering the underlying relationship between transformational leaders and followers' task performance. Journal of Personnel Psychology, 13(4), 194-203. http://dx.doi.org/10.1027/1866-5888/a000118

Burns, J. M. (1978). Leadership. Harper \& Row.

Cathal, R., Bergin, M., \& Wells, S.G., J. (2021). Work-related stress and wellbeing of direct care workers in intellectual disability services: a scoping review of the literature, International Journal of Developmental Disabilities, 67(1), 1-22. http://dx.doi.org/10.1080/20473869.2019.1582907

Chebon, S. K., Aruasa, W. K., \& Chirchir, L. K (2019). Influence of individualized consideration and intellectual stimulation on employee performance: lessons from Moi Teaching and Referral Hospital, Eldoret, Kenya. IOSR Journal of Humanities and Social Science, 24(7), 11-22. http://dx.doi.org/10.9790/0837-2407041122

Choi, S. B., Kim, K., \& Kang, S. W. (2017). Effects of transformational and shared leadership styles on employees' perception of team effectiveness. Social Bebaviour and Personality: An International Journal, 45(3), 377386. https://doi.org/10.2224/sbp.5805

Chua, J., \& Ayoko, O. B. (2019). Employees' self-determined motivation, transformational leadership and work engagement. Journal of Management \& Organization, 1-21. https://doi.org/10.1017/jmo.2018.74

Cox, T. \& Griffiths, A. (1995). The assessment of psychosocial hazards at work, in Shabracq, M. J., Winnubst, J. A. M. and Cooper, C. L. (eds.), Handbook of Work and Health Psychology, Wiley \& Sons, Chichester.

Cox, A. D., Leung, J., Anderson, B. M., \& Morgan, M.-C. (2021). Examining research patterns in the treatment of adults with problem behaviour and intellectual and developmental disabilities: A brief review. Behavioural Development, 26(1), 14-28. https://doi.org/10.1037/bdb0000100

Day, D. V., Gronn, P., \& Salas, E. (2004). Leadership capacity in teams. The Leadership Quarterly, 15(6), 857-880. https://doi.org/10.1016/j.leaqua.2004.09.001

Devereux, J. M., Hastings, R. P., Noone, S. J., Firth, A. \& Totsika, V. (2009). Social support and coping as mediators or moderators of the impact of work stressors on burnout in intellectual disability support staff. Research in Developmental Disabilities 30, 367-77. https://doi.org/10.1016/i.ridd.2008.07.002

Dumdum, U. R., Lowe, K. B., \& Avolio, B. J. (2013). A meta-analysis of transformational and transactional leadership correlates of effectiveness and satisfaction: And update and extension. In B.J. Avolio \& F.J. Yammarino, Emerald Group Publishing Limited (Eds.), Transformational and Charismatic Leadership: The Road Ahead (2nd ed., pp. 39-71) Elsevier Science.

Edú V., S., Moriano L., J. A., Molero A., F., \& Topa C., G. (2012). Authentic leadership and its effect on employees' organizational citizenship behaviours. Psicothema, 24(4),561-566. http://www.psicothema.com/pdf/4054.pdf?

Erskine, J.A.K, \& Georgiou, G.J. (2017). Leadership styles: Employee stress, well-being, productivity, turnover and absenteeism. Understanding Stress at Work, 28-40. http//hayka-kultura.org/larsen.html

Eurofound (2017). Sixth European Working Conditions Survey - Overview report (2017 update). Office of the European Union. https://www.eurofound.europa.eu/publications/report/2016/working -conditions/sixth-european-working-conditions-survey-overviewreport

Eurofound (2019). Working conditions and workers' health. Office of the European Union. https://www.eurofound.europa.eu/publications/report/2019/working -conditions-and-workers-health

Eurofound, \& EU-OSHA (2014). Psychosocial risks in Europe: prevalence and strategies for prevention. Office of the European Union. https://osha.europa.eu/en/publications/psychosocial-risks-europeprevalence-and-strategies-prevention

European Agency for Safety and Health at Work (EU-OSHA) (2019). Third European Survey of Enterprises on New and Emerging Risks (ESENER 3).
Luxembourg: Office for Official Publications of the European Communities. https://osha.europa.eu/es/publications/third-europeansurvey-enterprises-new-and-emerging-risks-esener-3/view

Figueiredo-Ferraz, H., Gil-Monte, P. R., Ribeiro, B. R., \& Grau-Alberola, E. (2013). Influence of a cognitive behavioural training program on health A study among primary teachers. Journal of Psychodidactics, 18(2), 343-356. https://doi.org/10.1387/revpsicodidact.6995

Fladerer, M.P. \& Braun, S. (2020). Managers' Resources for Authentic Leadership - a Multistudy Exploration of Positive Psychological Capacities and Ethical Organizational Climates. British Journal of Management 31, 325-343. https://doi.org /10.1111/1467-8551.12396

García-Guiu, L., C., Molero A., F., Moya M., M., \& Moriano L., J. A. (2015). Authentic leadership, group cohesion and group identification in security and emergency teams. Psicothema, 27(1), 59-64. https://doi.org /10.7334/psicothema2014.161

Gardner, W. L., Lowe, K. B., Meuser, J. D., Noghani, F., Gullifor, D. P., \& Cogliser, C. C. (2020). The leadership trilogy: A review of the third decade of the leadership quarterly. The Leadership Quarterly, 31(1), 101379. https://doi.org/10.1016/j.leaqua.2019.101379

Gilbert, M. H., Dagenais-Desmarais, V., \& St-Hilaire, F. (2017). Transformational leadership and autonomy support management behaviours: The role of specificity in predicting employees' psychological health Leadership and Organization Development Journal, 38(2), 320-332. https://doi.org/10.1108/LODJ-08-2015-0173

Gil-Monte, P. R. (2016). La Batería UNIPSICO: propiedades psicométricas de las escalas que evalúan los factores psicosociales de demanda. [The UNIPSICO Battery: psychometric properties of the scales that assess psychosocial demand factors]. Archivos de Prevención de Riesgos Laborales, 19(2), 86-94. http://dx.doi.org/10.12961/aprl.2016.19.02.3

Gonzalez-Mulé, E., \& Cockburn, B. S. (2020). This job is (literally) killing me: A moderated-mediated model linking work characteristics to mortality. Journal of Applied Psychology, 106(1), 140151. https://doi.org/10.1037/apl0000501

Green, A.E., Miller, E.A., \& Aarons, G.A. (2013). Transformational leadership moderates the relationship between emotional exhaustion and turnover intention among community mental health providers. Community Mental Health Journal 49,373-379. https://doi.org/10.1007/s10597-011-9463-0

Gu B., Tan Q., \& Zhao S. (2019). The association between occupational stress and psychosomatic wellbeing among Chinese nurses: A cross$\begin{array}{llll}\text { sectional survey. Medicine, } & \text { 98(22)- } & \text { p } & \text { e15836 }\end{array}$ .https://doi.org/10.1097/MD.0000000000015836

Haile, G.A. (2012). Unhappy working with men? Workplace gender diversity and job-related well-being in Britain. Labour Economics, 19(3), 329-350. https://doi.org/10.1016/j.labeco.2012.02.002.

Hatton, C., Emerson, E., Rivers, M., Mason, H., Mason, L., Swarbrick, R., Kiernan, C., Reeves, D., \& Alborz, A. (1999). Factors associated with staff stress and work satisfaction in services for people with intellectual disability. Journal of Intellectual Disability Research, 43, 253-267. https://doi.org/10.1046/j.1365-2788.1999.00208.x

Hayes, A. F. (2018). Introduction to Mediation, Moderation, and Conditional Process Analysis: A Regression-Based Approach (2nd ed.). The Guilford Press. https://www.guilford.com/books/Introduction-to-MediationModeration-and-Conditional-Process-Analysis/AndrewHayes/9781462534654

Heidarimoghadam, R., Saidnia, H., Joudaki, J., Mohammadi, Y., \& Babamiri, M. (2019). Does mental workload can lead to musculoskeletal disorders in healthcare office workers? Suggest and investigate a path. Cogent Psy. chology, 6(1), 1-8. https://doi.org/10.1080/23311908.2019.1664205

Hentrich, S., Zimber, A., Garbade, S. F., Gregersen, S., Nienhaus, A., \& Petermann, F. (2017). Relationships between transformational leadership and health: The mediating role of perceived job demands and occupational self-efficacy. International Journal of Stress Management, 24(1), 34-61. http://dx.doi.org/10.1037/str0000027

Holstad, T. J., Korek, S., Rigotti, T., \& Mohr, G. (2014). The relation between transformational leadership and follower emotional strain: The moderating role of professional ambition. Leadershit, 10, 269-288. http://dx.doi.org/10.1177/1742715013476083

Horstmeier, C.A.L., Boer, D., Homan, A.C. \& Voelpel, S.C. (2017). The Differential Effects of Transformational Leadership on Multiple Identi- 
fications at Work: A Meta - analytic Model. British Journal of Management, 28(2), 280-298. https://doi.org/10.1111/1467-8551.12160

Johnson, S., Robertson, I., \& Cooper C. L. (2018). Well-being: Productivity and happiness at work (2nd ed.). Palgrave MacMillan. https://www.palgrave.com/gp/book/9781349321032

Kedenburg, G. L., (2014). Examining the Interaction Between Leadership Style and Organizational Justice and its Effect on Organizational Commitment, Job Satisfaction, and Work Stress. Masters Theses \& Specialist Projects. Paper 1408. https://digitalcommons.wku.edu/theses/1408

Klaver, M., van den Hoofdakker, B. J., Wouters, H., de Kuijper, G., Hoekstra, P. J., \& de Bildt, A. (2021). Exposure to challenging behaviours and burnout symptoms among care staff: the role of psychological resources. Journal of Intellectual Disability Research, 65(2), 173-185. https://doi.org/10.1111/jir.12800

Kozak, A., Kersten, M., Schillmöller, Z., \& Nienhaus, A. (2013). Psychosocial work-related predictors and consequences of personal burnout among staff working with people with intellectual disabilities. Research in Developmental Disabilities, 34(1), 102-115. https://doi.org/10.1016/j.ridd.2012.07.021

Llorent, V. J., \& Ruiz-Calzado, I. (2016). Burnout and its relation to sociodemographic variables among education professionals working with people with disabilities in Córdoba (Spain).Ciência \& Saúde Coletiva, 21(10), 3287-3295. https://doi.org/10.1590/1413812320152110.00732015. PMID: 27783801.

Lievens, F., Van Geit, P., \& Coetsier, P. (1997) Identification of Transformational Leadership Qualities: An Examination of Potential Biases. European Journal of Work and Organizational Psychology, 6(4), 415-430. https://doi.org/10.1080/135943297399015

McCauley, C. \& Palus, C.J. (2020). Developing the theory and practice of leadershio development: A relational view. The Leadership Quaterly, 101456 https://doi.org/10.1016/j.leaqua.2020.101456

Mills, S. \& Rose, J. (2011), The relationship between challenging behaviour, burnout and cognitive variables in staff working with people who have intellectual disabilities. Journal of Intellectual Disability Research, 55, 844857. https://doi.org/10.1111/j.1365-2788.2011.01438.x

Mohanraj, P. (2017). An investigation on the impact of the factors of quality of worklife on socio-psychological aspects of the workers. International Journal of Research and Innovation in Social Science (IJRISS), 1(3), 14-21. http://www.ijriss.org/DigitalLibrary/Vol.1\&Issue3/14-21.pdf

Montano, D. (2016). Supervisor behaviour and its associations with employees' health in Europe. International Archives of Occupational and Environmental Health, 89(2), 289-298. https://doi.org/10.1007/s00420-0151072-8

Moriano, J. A., Molero, F., \& Lévy Mangin, J. P. (2011). Liderazgo auténtico. Concepto y validación del cuestionario ALQ en España. [Authentic leadership. Concept and validation of the ALQ in Spain]. Psicothema, 23(2), http://www.psicothema.com/psicothema.asp?id=3891

Morsiani G., Bagnasco A. \& Sasso L. (2017). How staff nurses perceive the impact of nurse managers' leadership style in terms of job satisfaction: a mixed method study. Journal of Nursing Management 25, 119-128. https://doi.org/10.1111/jonm.12448

Noreen, S., Nisar, Q. A., Haider, S., \& Yean, T. F. (2021). Role of Leaders' Emotional Labor toward Leader's Job Satisfaction and Emotional Exhaustion: Moderating Role of Psychological Capital. Gadjah Mada International Journal of Business, 23(1), 36-54. https://doi.org/10.22146/gamaijb.53996

Nyberg, A. (2009). The impact of managerial leadership on stress and health among employees. Stockholm, Sweden: Karolinska Institute.

Nunnally, J. C. (1978). Psychometric theory. McGraw-Hill.

Oros, L., Vargas-Rubilar, N., \& Chemisquy, S. (2020). Estresores docentes en tiempos de pandemia: Un instrumento para su exploración [Teachers' stressors in times of pandemic: an instrument for their exploration]. Revista Interamericana de Psicologia/Interamerican Journal of Psychology, 54(3), e1421-e1421. https://doi.org/10.30849/ripijp.v54i3.1421

Peláez, Z., M.J., Coo C., C., Martínez, I.M.,\& Salanova, M. (2021). Development and validation of the coaching-based leadership scale and its relationship with psychological capital, work engagement, and performance. Current Psychology. https://doi.org/10.1007/s12144-021-01460-w

Pierro, A., Raven, B. H., Amato, C., \& Bélanger, J. J. (2013). Bases of social power, leadership styles, and organizational commitment. International Journal of Psychology, 48(6), 1122-1134. https://doi.org/10.1080/00207594.2012.733398

Ribeiro, N., Yücel, İ. \& Gomes, D. (2018). How transformational leadership predicts employees' affective commitment and performance. International Journal of Productivity and Performance Management, 67(9), 1901-1917. https://doi.org/10.1108/IJPPM-09-2017-0229

Skakon, J., Nielsen, K., Borg, V., \& Guzman, J. (2010). Are leaders' wellbeing, behaviours and style associated with the affective well-being of their employees? A systematic review of three decades of research. Work $\quad \& \quad$ Stress, $24(2), \quad 107$ 139. https://doi.org/10.1080/02678373.2010.495262

Shukla, S., \& Shukla, S. (2020). Organizational discourse and dysfunctional leadership. The Psychologist-Manager Journal, 23(1), 1-11. https://doi.org/10.1037/mgr0000094

Sosik, J.J., \& Jung, D. (2018). Full Range Leadership Development: Pathways for People, Profit, and Planet (2nd ed.). Routledge. https://doi.org/10.4324/9781315167206

Specchia, M.L.; Cozzolino, M.R.; Carini, E.; Di Pilla, A.; Galletti, C.; Ricciardi, W. \& Damiani, G. (2021). Leadership Styles and Nurses' Job Satisfaction. Results of a Systematic Review. International Journal of Environmental Research and Public Health, 18, 1552. https://doi.org/10.3390/ijerph18041552

St-Hilaire, F., Gilbert, M. H., \& Lefebvre, R. (2018). Managerial practices to reduce psychosocial risk exposure: A competency-based approach. $\mathrm{Ca}$ nadian Journal of Administrative Sciences/Revue Canadienne des Sciences de l'Administration, 35(4), 535-550. https://doi.org/10.1002/CJAS.1506

Syrek, C. J., \& Antoni, C. H. (2017). Psychological contract fulfillment and employee responses to pay system change: The effects of transformational leadership. Journal of Personnel Psychology, 16(4), 172185. https://doi.org/10.1027/1866-5888/a000186

Syrek, C. J., Apostel, E., \& Antoni, C. H. (2013). Stress in highly demanding IT jobs: Transformational leadership moderates the impact of time pressure on exhaustion and work-life balance. Journal of Occupational Health Psychology, 18(3), 252-261.https://doi.org/10.1037/a0033085

Toderi, S., Gaggia, A., Balducci, C., \& Sarchielli, G. (2015). Reducing psychosocial risks through supervisors' development: A contribution for a brief version of the "Stress Management Competency Indicator Tool". Science of the Total Environment, 518-519, 345-351. https://doi.org/10.1016/j.scitotenv.2015.02.082

Van Aerden, K., Puig-Barrachina, V., Bosmans, K., \& Vanroelen, C. (2016). How does employment quality relate to health and job satisfaction in Europe? A typological approach. Social Science \& Medicine, 158, 132-140. https://doi.org/10.1016/j.socscimed.2016.04.017

Van der Meer, L., Nieboer, A. P., Finkenflügel, H., \& Cramm, J. M. (2018) The importance of person-centred care and co-creation of care for the well-being and job satisfaction of professionals working with people with intellectual disabilities. Scandinavian Journal of Caring Sciences, 32(1), 76-81. https://doi.org/10.1111/scs.12431

Van Stolk C., Staetsky, L., Hassan E. \& Woo K., Ch. (2012). Management of psychosocial risks at work: an analysis of the findings of the european survey of enterprises on new and emerging risks (ESENER) European Risk. Observatory Report. Edited by Malgorzata Milczarek and Xabier Irastorza, European Agency for Safety and Health at Work (EU-OSHA). https://osha.europa.eu/en/publications/management-psychosocialrisks-work-analysis-findings-european-survey-enterprises-new

Wang, D., Waldman, D. A., \& Zhang, Z. (2014). A meta-analysis of shared leadership and team effectiveness. Journal of Applied Psychology, 99(2), 181-198.https://doi.org/10.1037/a0034531

World Medical Association (2013). World Medical Association Declaration of Helsinki: Ethical Principles for Medical Research Involving Human Subjects. JAMA, 310(20), 2191-2194. https://doi.org/10.1001/jama.2013.281053

Yukl, G. A. (2013). Leadership in organizations. Boston: Pearson. 